Relations industrielles

Industrial Relations

\title{
Rapport de la Commission d'enquête sur l'observance du dimanche dans les usines de pâtes et papiers du Québec. Gouvernement de la province de Québec, 1966. 75 pages.
}

\section{Paul Bouchard}

Volume 22, numéro 1, 1967

URI : https://id.erudit.org/iderudit/027766ar

DOI : https://doi.org/10.7202/027766ar

Aller au sommaire du numéro

Éditeur(s)

Département des relations industrielles de l'Université Laval

ISSN

0034-379X (imprimé)

1703-8138 (numérique)

Découvrir la revue

Citer ce compte rendu

Bouchard, P. (1967). Compte rendu de [Rapport de la Commission d'enquête sur l'observance du dimanche dans les usines de pâtes et papiers du Québec.

Gouvernement de la province de Québec, 1966. 75 pages.] Relations

industrielles / Industrial Relations, 22(1), 138-138.

https://doi.org/10.7202/027766ar

Tous droits réservés @ C Département des relations industrielles de l'Université Laval, 1967
Ce document est protégé par la loi sur le droit d'auteur. L'utilisation des services d’Érudit (y compris la reproduction) est assujettie à sa politique d'utilisation que vous pouvez consulter en ligne.

https://apropos.erudit.org/fr/usagers/politique-dutilisation/ 
Lo pésentotion des données est présidée de notes explicatives de foçon à faciliter la lecture et la compilation des données. Ces notes techniques tentent de situer le cadre et la portée de l'enquête, de préciser les termes et les définitions employés et d'expliquer le coroctère des réponses et des résultots

On trouve oussi en oppendice le questionnaire distribué aux différents établissements, en plus du tableou complet des conditions de travail portées à l'étude de 1957-1964. La compilation des données se divise en deux parties, distinguant les employés de bureaux des employés hors bureaux. Le questionnaire, présenté en appendice, prévoyait des espaces distincts pour ces deux catégories de travailleurs.

Chaque partie offre la même présentation. En effet, les données relatives d̀ chaque condition de travail à l'étude sont regroupées en section: dans la première section, couvront l'ensemble des industries, les données sont distribuées de façon à permettre la lecture pour l'ensemble du Canada et pour chaque province; dans la deuxième section, la distribution des données s'établit par industrie selon une classification présentée oux pages 11 et 111 de la table des matières.

Même si cette étude n'est pos exhaustive, ce rapport bilingue permet d'apprécier la qualité de certaines conditions de travail offertes aux travailleurs canadiens, et même, dans certains cos, en se référant aux rapports antérieurs, de suivre l'évolution qui s'est manifestée ou cours des dernières années.

\section{Gilles RICHARD}

\section{Rapport de la Commission d'enquête sur} l'observance du dimanche dans les usines de pâtes et papiers du Québec. Gouvernement de la province de Québec, 1966. 75 pages.

Cette commission d'enquête a été instituée pour obtenir des informations sur la production le dimanche dans les usines de pâtes et papiers, pour faire une étude approfondie de la question et pour proposer des normes d'application de la Loi du dimanche qui tiennent compte du contexte économique octuel, en établissant des distinctions valables entre nécessité économique et avantage économique d'une part, et nécessité technique et ovantoge technique d'autre part.

L'enquête se limite ou travail du dimanche dans les usines de pôtes et papiers de la
Province. Pour cette raison, les commissaires n'ont pos eu ò exominer les opérotions forestières le dimanche par des compagnnies de pâtes et papiers ou autres dans les forêts du Québec, ni le problème de production que rencontrent d'autres industries ou d'autres usines.

Dès le début de l'enquête, les cornmissaires définissent ce qu'ils entendent par usines de pâtes et papiers. II s'agit en quelque sorte de la fabrication même de la pâte et du papier mais non de leur transformation subséquente en d'autres produits. De plus, les commissaires ont dû fixé un point à portir duquel un avantoge économique important devient une nécessité économique. En effet faut-il attendre qu'une entreprise soit en difficultés financières avant de dire qu'il s'agit d'un cos de nécessité économique? II en vo de même en ce qui a trait à l'avantage technique et à la nécessité technique où des recherches considérables ont dû être entreprises.

Enfin, les commissaires ne se sont pas limités ò un strict examen du problème de la production du dimanche dans les usines de pôtes et papiers mais ont envisogé, de plus, les développements techniques de l'industrie, so situotion économique, sa participation au progrès de l'économie du Québec et ou bien commun, de mêrne que les répercussions sociales du travail dominical. Et c'est ò partir de toutes ces données, les unes impérotives, les autres indicotives, que les commissaires ont dressé la liste des recommandations qui leur semblaient appropriées et judicieuses eu égard aux diverses circonstances

\section{Paul BOUCHARD}

Japanese Trade Unionism, by Alice H. Cook New York State School of Industrial and Labor Relations, Cornell University, Ithaca, New York, 1966. 216 pages.

Le but que se propose d'atteindre l'auteur dans son étude est de fournir à ses lecteurs une description aussi complète que possible de la structure et des fonctions du syndicalisme japonais. L'auteur est bien placé d'ailleurs pour entreprendre un tel travail car il a passé, en tant que stagiaire, un an dans une université de Tokyo où il a contacté des professeurs éminents de l' « Institute of Management and Labor Studies .

Pour réaliser son objectif, l'auteur sélectionna dix syndicats qui se devaient d'être représentatifs de l'ensemble. C'est pourquoi, 